\title{
A Percepção do Tempo através do Processo de Envelhecimento
}

\section{La Percepción del Tiempo a través del Proceso de Envejecimiento}

The Perception of Time through the Aging Process

\section{Danilo Ribeiro do Nascimento Aragão}

ORCID: https://orcid.org/0000-0002-6797-2985

Universidade Católica de Brasília, Brasília/ Brasil

\section{Isabelle Patriciá Freitas Soares Chariglione ORCID: https://orcid.org/0000-0001-8627-3736 Universidade Católica de Brasília, Brasília/ Brasil}

Declaração de Direito Autoral

A submissão de originais para este periódico implica na transferência, pelos autores, dos direitos de publicação impressa e digital. Os direitos autorais para os artigos publicados são do autor, com direitos do periódico sobre a primeira publicação. Os autores somente poderão utilizar os mesmos resultados em outras publicações indicando claramente este periódico como o meio da publicação original. Em virtude de sermos um periódico de acesso aberto, permite-se o uso gratuito dos artigos em aplicações educacionais e científicas desde que citada a fonte conforme a licença CC-BY da Creative Commons.

\section{Resumo}

A população mundial está em um rápido processo de envelhecimento. O número de idosos na sociedade brasileira cresceu exponencialmente nas últimas décadas, assim como os estudos que objetivam investigar as dimensões do envelhecimento e correlacioná-lo com qualidade de vida. O percurso metodológico deu-se por análise qualitativa, com o software IRaMuTeQ, a respeito do processo de envelhecimento, pela percepção da passagem de tempo (Protensão) de idosos participantes de um projeto de intervenções cognitivas e físicas realizado na Universidade Católica de Brasília. Os resultados evidenciam melhoras entre os momentos pré e pós-intervenção; a percepção do tempo através do processo de envelhecimento está intimamente ligada a acrescimentos do uso da palavra "mais" em ambos os momentos; a associação entre as palavras mudam apontando passagens temporais aceleradas, evidenciando uma melhora psicológica. Com mais publicações a respeito do tema, será possível utilizar o fator "percepção de tempo" como variável para analisar qualidade de vida em idosos.

Palavras-chaves: Envelhecimento; Percepção; Tempo; Qualidade de vida.

\section{Resumen}

La población mundial está en un rápido proceso de envejecimiento. El número de ancianos en la sociedad brasileña creció exponencialmente en las últimas décadas, así como los estudios que objetivan investigar las dimensiones del envejecimiento y correlacionarlo con calidad de vida. El recorrido metodológico se dio por análisis cualitativo, con el software IRaMuTeQ, acerca del proceso de envejecimiento, por la percepción del paso de tiempo (Protensión) de ancianos participantes de un proyecto de intervenciones cognitivas y físicas realizado en la Universidad Católica de Brasilia. Los resultados evidencian mejoras entre los momentos pre y post-intervención; la percepción del tiempo a través del proceso de envejecimiento está íntimamente ligada a los agregados del uso de la palabra "más" en ambos momentos; la asociación entre las palabras cambian apuntando pasajes temporales 
acelerados, evidenciando una mejora psicológica. Con más publicaciones sobre el tema, será posible utilizar el factor "percepción de tiempo" como variable para analizar calidad de vida en ancianos.

Palabras claves: Envejecimiento; Percepción; Tiempo; Calidad de vida.

\begin{abstract}
The world population is in a rapid aging process. The number of elderly people in Brazilian society has grown exponentially in the last decades, as well as studies that aim to investigate the dimensions of aging and correlate it with quality of life. The methodological course was based on a qualitative analysis, with the IRaMuTeQ software, regarding the aging process, by the perception of the passage of time (Protension) of elderly participants of a project of cognitive and physical interventions carried out at the Catholic University of Brasília. The results show improvements between the pre- and postintervention moments; the perception of time through the aging process is intimately linked to additions to the use of the word "more" at both times; the association between words changes indicating accelerated temporal passages, evidencing a psychological improvement. With more publications on the subject, it will be possible to use the factor "time perception" as a variable to analyze quality of life in the elderly.
\end{abstract}

Keywords: Aging; Perception; Time; Quality of life.

\section{Introdução}

A população idosa mundial cresce a cada ano. Estima-se que, em 2020, para cada 13 brasileiros, um será idoso; em 2025, o Brasil será o $6^{\circ}$ país em uma escala mundial com maior população idosa (França, Barbosa, Fett, \& Fett, 2016). Para o Instituto Brasileiro de Geografia e Estatística (IBGE), em 2030, a taxa de crescimento populacional irá decair significativamente, se comparado aos anos 2000, e os indivíduos com 65 anos ou mais serão $13,44 \%$ da população, proporcionalmente, o maior índice já registrado no país. No Distrito Federal, o índice será de $11,68 \%$, contra os $7,15 \%$ de 2018 . Os números ainda são mais expressivos quando levado em consideração o Índice de Envelhecimento - número de pessoas de 60 ou mais, para cada 100 pessoas menores de 15 anos de idade. Em 2018, esse valor é de 40,28; em 2030, será de 76,39 (Instituto Brasileiro de Geografia e Estatística [IBGE], 2018).

O envelhecimento é fator preponderante à população brasileira, logo, a preocupação, em termos de qualidade de vida desse público, é motivo de investigação cada vez mais crescente nas pesquisas acadêmicas. Como um processo com múltiplos aspectos, é muito importante ter um olhar multidisciplinar a respeito desse tema, envelhecimento, já que se faz necessário preconizar o bem-estar biopsicossocial, não somente a ideia de tratar ou prevenir doenças. Também ter como premissas de que é um processo social e emocional, digno de constantes reflexões e ressignificações, sendo visto como proibido, vergonhoso, dependente da aceitabilidade social (França et al., 2016).

Falar sobre envelhecer é associar diretamente à idade. Segundo Papaléo Netto (2013), cabe debater as perspectivas de idade biológica e cronológica, esta associada ao ciclo, ou seja, aos aniversários completos, os anos. O olhar sob a idade biológica é de difícil definição, já que não há consenso em seu início. Ainda é possível considerar uma terceira vertente: a idade psicológica, que apresenta uma intimidade com a cronológica e versa sobre as potencialidades cognitivas do sujeito. Este modelo evidencia a subjetividade do sujeito perante sua idade, sendo que cada pessoa tem sua percepção sobre a passagem do tempo, sendo biológica e/ou psicológica, predispondo-se a comparar com outros sujeitos da mesma idade cronológica. Preserva-se de que a idade psicológica seja menor que a idade 
cronológica e essa comparação tende a um caráter de autoestima e imagem social.

No desenrolar da vida, alguns conceitos se misturam, como: envelhecimento, velhice, velho e idoso, e, embora se relacionem o tempo todo, não podem ser utilizados como sinônimos. Envelhecimento é um processo que se inicia na concepção e acaba com a morte, é inerente a todos os seres vivos, logo, está intrínseca sua relação com a idade biológica. Por se tratar de algo contínuo, é de difícil conceituação exata, pois se fixam ao termo as características de alteração biopsicossocial do sujeito, afetando sua homeostase, ampliando as dificuldades de adaptação ao seu meio. Velhice vem acompanhada de uma reputação muito ruim, é socialmente entrelaçada à incapacidade, à decadência. Por outro lado, é a última fase do ciclo de vida na qual se apresenta a maior quantidade de manifestações somáticas e psicossociais associadas ao processo de envelhecimento. Velho é um estado, é como sentir-se, é a estereotipia da velhice. Sujeitos que não estão no ciclo da velhice apresentam as características tais como se estivessem se sentindo "velhos". O conceito de idoso advém do marco da idade cronológica de 60 anos, apropria-se de características da "velhice" como a última fase do desenvolvimento humano e a maior prevalência de declínios físicos, funcionais, psicológicos e sociais; é a faceta política do sujeito acima dos 60 anos (Ferreira, Maciel, Silva, Sá, \& Moreira, 2010; Santos, 2010).

Envelhecer não é um processo fácil, o tempo cronológico passa ininterruptamente, e por muito passa despercebido pelo sujeito. Apesar de um lugar desejado, não perde sua complexidade, é um momento onde as perdas estão mais presentes e tornam-se mais reais do que já foram.

Considerando a perspectiva de qualidade de vida, a investigação da vivência desse envelhecimento é um ponto importante para a manutenção do bem-estar. O tempo, o espaço e suas facetas são objetos de estudos a milhares de anos, pois são fatores fundamentais à vida e ao comportamento, em suas dimensões todos estão contidos, e essa relação fornece experiências estruturantes. Ao contrário de outros fatores que são percebidos pelos órgãos sensoriais, o tempo não ativa nenhuma área neuronal. Não se tem neurônios sensitivos especializados à percepção do tempo, entretanto, isso não diminui de forma alguma o peso das experiências. Por outro lado, a percepção do tempo, geralmente, é associada a características biológicas e psicológicas, como a presença de rugas, desgastes físicos, aquisição de experiências etc. (Buhusi \& Meck, 2005; Sampaio, 2016).

Os estudos sobre tempo não possuem uma data inicial, mas sabe-se que sempre moveu a curiosidade de intelectuais de diversas áreas. Possivelmente, representações mais marcantes, historicamente, dão-se, a partir da cultura mitológica greco-romana, para auxiliar na compreensão dos "tempos modernos", com o surgimento de Cronos e Kairós, que colocam os sujeitos em uma dualidade temporal. Cronos (Kronos, em grego), deus grego, senhor do universo, e ainda o tempo que tudo devora, mensurável, quantificado por horas dias etc. É a premissa para segmentar a vida em fases, é a cronologia ritmada e linear, onde não existe passado e lembranças. Por outro lado, Kairós, que significa "o momento" certo, em grego, e momentum (instante, ocasião ou movimento), em latim, é o deus mais jovem do Olimpo, o caçula de Zeus, é o tempo vivencial, independente da cronologia, onde não há fases de vida, sendo cíclica e não linear (Bertamoni, 2009).

A Psicologia dedica-se a estudar esses fenômenos, e sua ênfase cognitiva não fica de fora. Em busca de instrumentalizar a análise científica, que permite decifrar a percepção da passagem do tempo, dividiu-se o tempo em três partes (Buhusi \& Meck, 2005; Sternberg, 2012):

- Tempo objetivo: é a faceta mesurável, usada como medida passível de contagem pelo relógio. Nessa modalidade, evidencia-se que os processamentos de diferentes estímulos são realizados em locais diferentes no sistema nervoso central (SNC), indicando uma 
diferenciação linear e cronológica no tratamento dessas informações.

- Tempo implícito (automático): é a modalidade de tratamento de informação pelo cérebro. Segundo Stetson, Cui, Montague e Eagleman (como citado em Sampaio, 2016, p. 376), o cérebro forma blocos de informações para processá-los, constituindo, assim, na percepção dos estímulos.

- Tempo subjetivo (explícito): é o resultado consciente da passagem de tempo, após o processamento cerebral dos estímulos.

A passagem subjetiva do tempo é um material denso para o olhar psicológico. Nesse caso, a quantificação física do tempo fica em segundo plano, o objeto de interesse está na percepção dos sujeitos perante o tempo, que é batizada como Protensão. Recebe esse nome com o intuito de separar o "tempo" de uma duração objetiva, mensurável para o "tempo" em sua percepção subjetiva, ou seja, a duração da qual se tem consciência (Schiffman, 2005).

O mundo fornece estímulos diversos todo o tempo, e o conhecimento desse mundo depende crucialmente dos sentidos. Contudo, é importante salientar que o mundo que se apresenta aos sentidos não corresponde necessariamente à exatidão da realidade concreta (Schiffman, 2005).

A percepção pode ser estruturada como uma referência final dos processos psicológicos, fomentados nas experiências e na memória. Ou seja, são os processos cognitivos envolvidos na organização, interpretação e atribuição de sentidos e significados conscientes, aos estímulos vindos dos órgãos sensoriais por eventos ambientais (Schiffman, 2005; Sternberg, 2012).

Sendo o tempo um fator tão preponderante para a existência, foram desenvolvidas duas grandes bases para entender melhor esse fenômeno de percepção temporal. A primeira é uma possível base biológica para percepção do tempo. De uma forma adaptativa, as espécies obedecem a um ciclo entre o dia e a noite (claro e escuro), que estão associados a mecanismos de variações metabólicas e de temperatura. Ciclos que estão sujeitos a uma regularidade de dia e noite são denominados ciclos (ou ritmos) circadianos. O termo circadiano provém do latim $\operatorname{circ} a=$ cerca de e dies $=$ dia, primeira vez cunhado por Franz Halberg para determinar um período rítmico de aproximadamente 24 horas, e ocorre quando um organismo se encontra isolado de pistas ambientais temporais, sendo expresso através do processo de sincronização. Esses ciclos circadianos parecem estar intimamente associados à luz solar. Em humanos, os estímulos oriundos da exposição solar perpassam pelo sistema ocular, atingindo determinadas áreas do cérebro, como a glândula pineal, responsável por produzir a melatonina, hormônio que auxilia na manutenção desse ciclo circadiano (Gonçalves \& Marques, 2012; Martynhak, Back, \& Louzada, 2012; Schiffman, 2005).

Em suma, o ciclo circadiano tem uma influência direta no comportamento humano, o que estrutura a proposta de um relógio biológico endógeno para a percepção do tempo. Em 1729, De Mairan, um astrofísico francês, apresentou um relato com certa cientificidade sobre a existência de um ritmo endógeno. Usando como base essa ideia, Hoagland propunha que, no SNC, exista um relógio biológico que funciona como uma espécie de detector de tempo, indo de acordo com o metabolismo que afeta a percepção do tempo, principalmente sob a vertente da velocidade superestimando ou subestimando a passagem do tempo, como, por exemplo, acredita-se que o período circadiano diminua com o passar da idade (Gonçalves \& Marques, 2012; Martynhak et al., 2012; Schiffman, 2005).

Cabe considerar que estímulos internos podem alterar essa percepção, como o uso de drogas lícitas e/ou ilícitas. Existem, ainda, fortes indícios de que alterações genéticas em animais e plantas também alteram significativa esse processo, por exemplo, drogas dopaminérgicas afetam seletivamente a velocidade subjetiva do relógio interno, e drogas colinérgicas agem sob o 
armazenamento da memória. Em humanos, o rastreio genético ainda é fortemente debatido (Buhusi \& Meck, 2005).

O modelo de relógio interno ainda assume outra vertente, descrita inicialmente por Treisman (1963) e, anos mais tarde, aprimorado por Meck (1996). Esse sistema utiliza-se de ferramentas psicofísicas para explicar e/ou prever os resultados de experimentos comportamentais e neurofisiológicos. De acordo com esse modelo, diferentes áreas do cérebro tendem a emitir disparos elétricos e, quando se desloca a atenção a determinado estímulo que envolva fatores temporais, uma espécie de acumulador de pulsos é ativada no cérebro. Logo, os disparos são realizados em blocos, que acessam e evocam memórias de trabalho e de referência (que é a responsável por armazenar os conteúdos temporais já experienciados), esta é fase de memória, levando a respostas embasadas na teoria da expectativa escalar, onde o produto é controlado pela comparação entre a razão da leitura subjetiva atual de tempo e uma amostra já retida das durações lembradas. Ou seja, um sistema de comparação entre as informações: verifica-se a duração do estímulo ativo, papel da memória de trabalho, e compara-se com uma duração média evocada pela memória de referência resultando em uma resposta (Buhusi \& Meck, 2005).

Se existe uma consolidada teoria biológica, outra vertente propõe teorias que percebem o tempo através de processos mentais, mais especificamente, a experiência da passagem do tempo é uma construção cognitiva, ou seja, "é um produto derivado da atividade mental que se baseia na natureza e na extensão dos processos cognitivos realizados durante um dado intervalo de tempo" (Schiffman, 2005, p. 361).

As teorias cognitivas ganham força com a proposta de Robert Ornstein: o tamanho do armazenamento de informações. $\mathrm{O}$ autor parte do pressuposto de que a quantidade e a complexidade de determinados eventos na vida do indivíduo, em conjunto com a eficiência de organização, codificação e armazenamento dos eventos, afetam diretamente a quantidade de informações que precisam ser processadas, fato este que influência fortemente a experiência de passagem de tempo. Ou seja, a quantidade de informações colhidas de forma consciente, organizadas e que forem armazenadas na memória irão determinar a percepção de duração de tempo. Para Ornstein, a quantidade de eventos ocorridos em determinado período de tempo irá alterar a percepção da passagem de tempo. Em testes, espaços vazios, intervalos de tempo sem ocorrência direto de eventos tendem a ser ansiogênicos, alterando a percepção de tempo. Logo, eventos onde exista o atravessamento emocional são passíveis de alteração no fenômeno de Protensão (Schiffman, 2005; Sternberg, 2012)

$\mathrm{O}$ fator emocional possui uma influência direta sobre a percepção da passagem do tempo, já que existe uma íntima relação entre memória e emoção, pois a emoção determina a qualidade do registro na memória. Estudos demonstram que a emoção é um fator determinante que influencia e modula o sistema cognitivo, por ser preponderante na memória. Portanto, em termos de processo de memória, quanto maior o volume emocional envolvido naquela experiência, mais este registro terá uma espécie de privilégio, que faz com que essa informação seja facilmente resgatada. Exemplificando, se o indivíduo tem a vivência de dois momentos relativamente idênticos (em estímulos e ações), em um terceiro a primeira lembrança a ser resgatada será aquela que ele presenciou com maior emoção, e logo depois o outro momento menos emotivo. Para Ornstein, os eventos ditos "desagradáveis" para o sujeito possuem uma duração mais curta de tempo; já aqueles experienciados com emoções mais agradáveis, quando evocados pela memória, serão considerados mais longos (Bear, Connors, \& Paradiso, 2008; Esperidião-Antonio et al., 2008; Kandel, Schwartz, \& Jessell, 2003; Purves et al., 2010). Com isso, quanto mais eventos armazenados na memória, em um determinado período de tempo, aparentemente terá uma maior duração. 
A estimativa temporal é influenciada no que versa a quantidade de atenção direcionada a ela, e ainda sob a perspectiva em que o sujeito questionado é colocado. Essa posição do julgamento perceptivo, ao responder uma questão sobre a passagem do tempo, também é possível enviesar do resultado final. Ou seja, o julgamento é divido em duas vertentes (Menna-Barreto, Ades, \& Pesavento, 1990):

- Prospectivo: aquele onde o sujeito é orientado previamente a perceber a passagem do tempo em determinada experiência, a fim de deslocar o máximo de seu material consciente para este objetivo. Neste tipo, envolvem-se mais recursos da atenção do que da memória, por direcionar o foco apenas a uma tarefa; percebe-se o tempo com uma amplitude maior.

- Retrospectivo: nesta perspectiva, o sujeito não é informado; primeiro passa pela experiência e, a posteriori, emite sua percepção temporal. Aqui, a passagem temporal tende a ser mais acelerada se comparada com o modelo anterior, pois a atenção pode estar direcionada a diversos eventos, e, por envolver mais materiais mnemônicos do que atencional, acredita-se que quanto mais materiais para memória, correspondentemente, mais tempo se passou.

Por constituir os alicerces em teorias cognitivas, o ponto crucial provém do uso da memória para relativizar com o tempo. A memória pode ser definida como um meio para se reter as experiências ou a capacidade de se reter pequenos fluxos de tempo. Para Sternberg (2012), memória é um meio de se reter experiências passadas e utilizá-las no presente. Izquierdo (2011) descreve que "sou quem sou porque me lembro quem sou", ou seja, memória é o ato de conservar o passado através de representações mentais que, em algum momento, podem ser evocadas. Segundo ele, não há memória sem aprendizado, que é a própria aquisição da memória.

A memória, como um processo, permite certa coerência na ordem do pensar, é o organizador da história, favorecendo, assim, a capacidade de auto-organização o que, por sua vez, facilita aos sistemas estarem continuamente se autoproduzindo a partir de sua própria maquinaria interna, referindo-se aos mecanismos de armazenamento do que foi aprendido, tendo que tais representações préavaliam as consequências de ações futuras, sem comprometer em nada a integridade do sistema no desempenho da ação. Essa previsão de possíveis resultados é dada pela armazenagem de experiências. Logo que se aprende algo, a tendência é que a resposta comportamental consciente seja baseada nessa experiência anterior, entretanto, em situações de risco, a resposta está baseada no lado inconsciente ou inato do indivíduo, podendo ser luta, fuga ou imobilidade tônica (Berne et al., 2004; Fuentes et al., 2008; Izquierdo, 2011).

A terceira frente teórica chama-se Teoria Cognitivo-Atencional. Nesta proposta, o foco de atenção é o protagonista à percepção do tempo, sob a perspectiva da existência de duas dimensões que se relacionam o tempo todo, entretanto, são independentes: processador de informações e cronômetro cognitivo. Apesar de não dependerem um do outro, eles compartilham os mesmos mecanismos atencionais, sendo assim, o primeiro, que possui um caráter atemporal, é responsável por processar as informações da tarefa em execução; ao segundo cabe processar especificamente as informações temporais. Logo, por dividirem os recursos temporais, que são limitados, um será privilegiado em detrimento do outro. Na medida em que a atenção é direcionada à execução de determinada tarefa, a percepção do tempo ficará em outro plano, sendo "encurtado"; por outro lado, se o foco atencional estiver direcionado ao processamento do tempo, ele será percebido como mais "longo".

Apesar das diferenças teóricas, metodológicas e práticas entre as propostas biológicas e psicológicas a respeito da percepção da passagem do tempo, existe uma variável que une essas duas perspectivas, a idade. A percepção aos humanos é clarificada, ano após ano. Graças ao processo de envelhecimento biológico e ao aumento de experiências armazenadas na memória, o modo 
como se vivencia e se olha para esse movimento é de suma importância para perceber a passagem do tempo. Como visto anteriormente, a qualidade e a intensidade da memória são fatores cruciais para a protensão, portanto, o olhar do sujeito perante sua vida também influenciará em como ele vivenciou a passagem do tempo. Ora dar-se-á como algo automatizado, imperceptível, ora como algo memorável, como se tivesse vivido há pouco tempo. Segundo Schiffman (2005), a idade atual do sujeito tona-se referência para a percepção. Ele exemplifica comparando a proporção de experiências entre uma criança e um idoso, cujo peso temporal da passagem do tempo possui percepções diferentes entre eles. Para o primeiro, a passagem entre os anos parece ter uma duração maior; já para o idoso, que experienciou esse evento, o mesmo período de um ano parece passar mais rápido. Ou seja, é possível afirmar que existe uma influência direta da idade sobre a percepção da passagem do tempo.

Então, frente às informações apresentadas, este artigo tem por objetivo analisar a percepção da passagem do tempo em idosos, participantes de um projeto de intervenções cognitivas e atividade física, a respeito do processo de envelhecimento, em diferentes momentos.

\section{Materiais e métodos}

Trata-se de uma pesquisa transversal e exploratória com caráter qualitativo, para avaliação, mensuração e caracterização da percepção dos idosos perante a passagem do tempo através do processo de envelhecimento. O levantamento pré-intervenção foi realizado durante as aulas Stimullus e MEMO. Ao final da primeira aula, foi entregue um questionário e na aula seguinte, com a pergunta-alvo. No momento pós-intervenção, foi entregue o questionário no encontro final, após as atividades.

Participaram desta pesquisa no momento pré-intervenção 34 idosos, e no pósintervenção, 20, com faixa etária entre 60 e 90 anos, integrantes do projeto de intervenções cognitivas e físicas executado na Universidade Católica de Brasília (UCB). No que se refere aos participantes, os idosos que participaram dos dois momentos não foram necessariamente os mesmos, pois estes foram convidados a darem as suas respostas anonimamente nos dois momentos, não sendo possível controlálos nem os identificar dentro da amostra geral.

Foram incluídos idosos de qualquer sexo, com idade mínima de 60 anos, que não apresentasse declínio cognitivo significativo, que soubesse ler e escrever, sendo participante efetivo do projeto. Foram excluídos os participantes que apresentaram problemas de saúde no intervalo entre as coletas, que desistissem de participar do projeto, que não participaram das atividades ou que tiveram faltas acima de $50 \%$.

A pergunta-alvo - O que é o envelhecimento para você? - esteve associada aos questionários cognitivos, e foi apresentada nos dois momentos em um questionário perceptivo.

A coleta de dados deu-se em dois momentos: na acolhida dos idosos (julho de 2017) e após passarem pela intervenção Stimullus/MEMO e atividade física (julho de 2018), com um intervalo de um ano entre as coletas. Anterior ao início das atividades, os idosos foram submetidos a uma bateria de medidas psicológicas cognitivas e físicas e assinaram o Termo de Consentimento Livre e Esclarecido. Contudo, o interesse deste trabalho é de entender o processo de envelhecimento por um aspecto temporal, logo, será realizado um recorte apresentando e discutindo, apenas, o instrumento oriundo da questão dissertativa e as informações relacionadas a essa temática.

A quantificação das respostas foi dada por uma estatística descritiva, a partir da análise de gráficos. Os dados qualitativos e a resposta subjetiva passaram pela análise de conteúdo, aumentando, assim, as possibilidades de descobertas; por se tratar de uma análise qualitativa, não há respostas definidas. 
Os dados qualitativos foram analisados
pela interface $\mathrm{R}$, para análises multidimensionais de textos, e de questionários, o IRaMuTeQ, que é um software gratuito para análise de dados textuais, através de cálculos estatísticos, possibilitando a quantificação de dados sobre variáveis qualitativas, sendo uma ferramenta para análises subjetivas de conteúdo, fornecendo a possibilidade de comparar e entrelaçar produções diferentes. O IRaMuTeQ utiliza diferentes análises textuais e, neste trabalho, foi utilizada a análise de Classificação Hierárquica Descendente (CHD), escolhida como forma de facilitar e incrementar a análise; dessa forma, a CHD classifica segmentos dos textos, dividindo os conjuntos com base na frequência das formas reduzidas (Camargo \& Justo, 2013).

Para realizar a análise, foram agrupadas todas as respostas de cada pergunta subjetiva, para, então, o programa analisar apenas um corpus. A partir dessas análises em matrizes, o software organizou a análise dos dados em um dendograma, ou seja, um diagrama de árvore que mostra grupos formados por agrupamentos. Essa análise foi escolhida para obter classes selecionando os vocabulários semelhantes e diferentes entre si e, a partir dessas classes, foram criados temas para explicá-los.

\section{Resultados}

As respostas dos idosos foram transcritas da mesma forma como escrita por eles. Entretanto, foram realizados pequenos ajustes em três casos:

- Em alguns momentos, os idosos escreveram "mais", com o sentido de adversidade. Sendo assim o "mais" foi substituído por "mas".

- Pequenos erros de ortografia também foram corrigidos, já que o software iria reconhecê-los como novas palavras, fugindo, assim, do intuito desta análise.

- Alguns tendiam a copiar o enunciado da pergunta no início da resposta, neste caso, a cópia foi descartada e o restante, considerado como resposta, transcrito.

O processo de indexação dos dados ao software IRaMuTeQ geram diversos gráficos. Contudo, neste caso, apenas dois gráficos foram possíveis, o de similitude e a nuvem de palavras. Possivelmente pelo baixo número de sujeitos, por apenas uma pergunta-alvo e, consequentemente, a escassez de palavras, não foi possível gerar os demais gráficos.

Para o momento pré-intervenção, foi gerado o Gráfico de Similitude (Figura 1) e a nuvem de palavras (Figura 2).

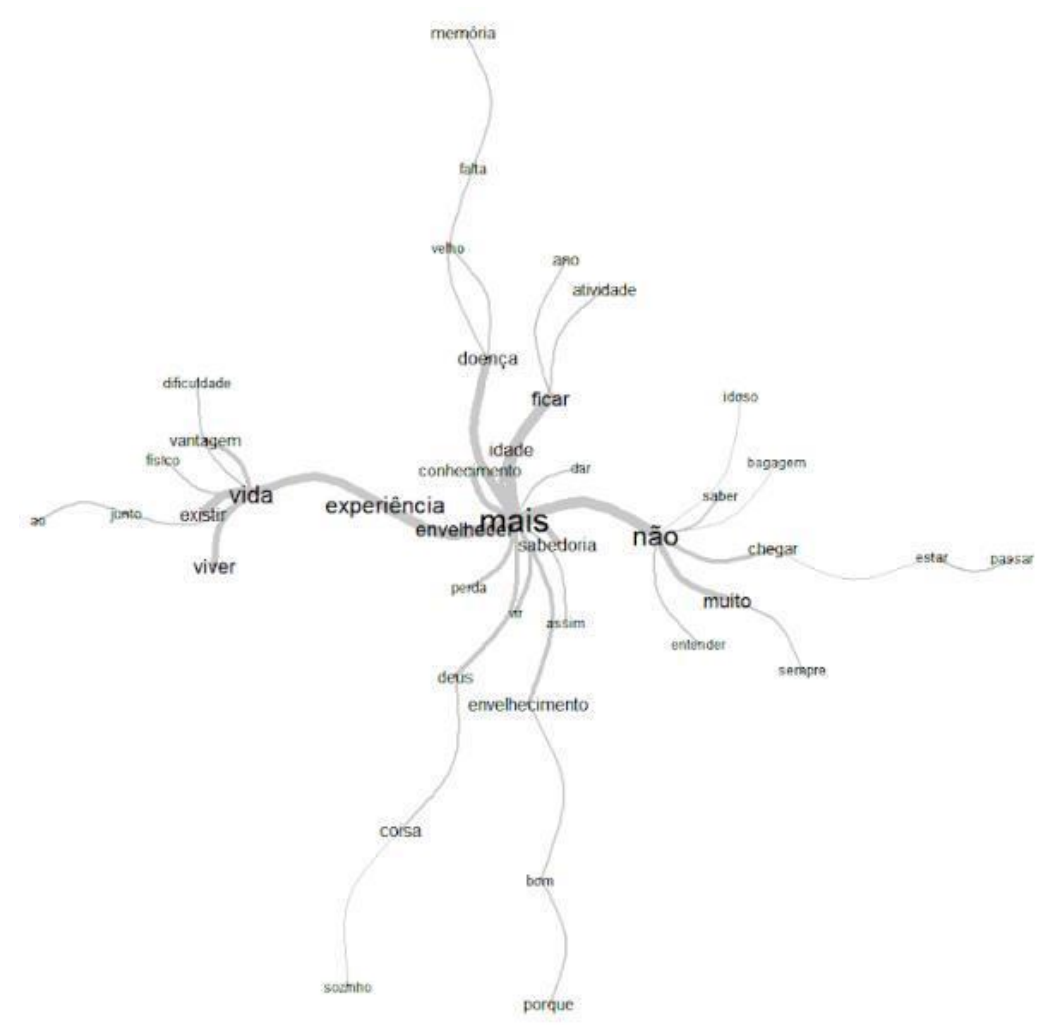

Figura 1. Combinação entre as palavras do conteúdo no momento pré-intervenção dos idosos do grupo NeuroCog-Idoso

Fonte: Dados gerados pelo software IRaMuTeQ a partir da análise dos resultados das entrevistas pré-intervenção 
Nesse sentido, pode-se perceber que no início das atividades foi destacado pelos idosos o entendimento positivo do processo de envelhecer, contemplado pelo "mais". Assim

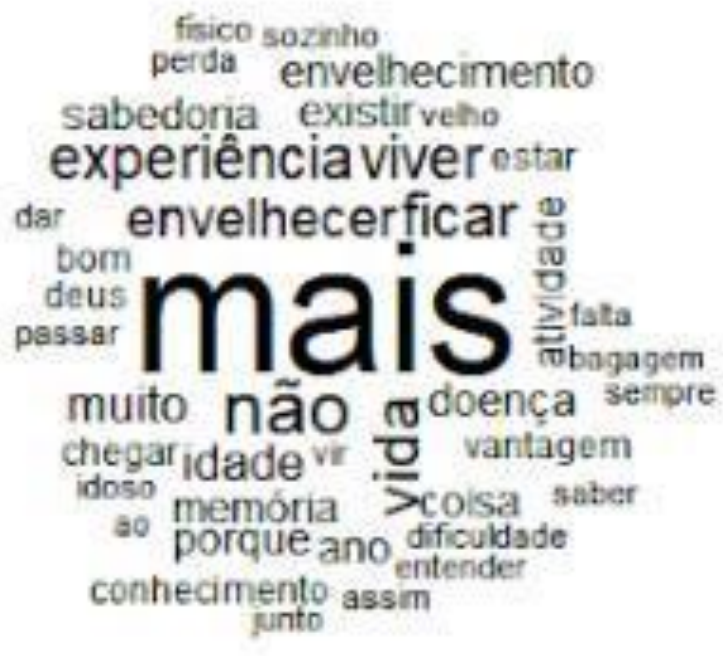

Figura 2. Nuvem de palavras do conteúdo no momento pré-intervenção dos idosos do grupo NeuroCog-Idoso

Fonte: Dados gerados pelo software IRaMuTeQ a partir da análise dos resultados das entrevistas pré-intervenção como, as limitações que o envelhecer pode trazer, como o "não entender", "não saber", e especialmente o "não muito" que também pode ser observado na Figura 2.

Na Figura 2, exalta-se a alta frequência do "mais" diante do uso de outras palavras. A posição centralizada e notoriamente maior que as demais é o resultado, por ser mais utilizada; o "não" aparece logo abaixo; também em evidência estão "experiência", "viver", "envelhecer" e "ficar". A análise apresentada na Nuvem de palavras corrobora o gráfico de similitude investigados no início das atividades do Grupo NeuroCog-Idoso no momento préintervenção.

Para o momento pós-intervenção, foi gerado o Gráfico de Similitude (Figura 3) e a nuvem de palavras (Figura 4).

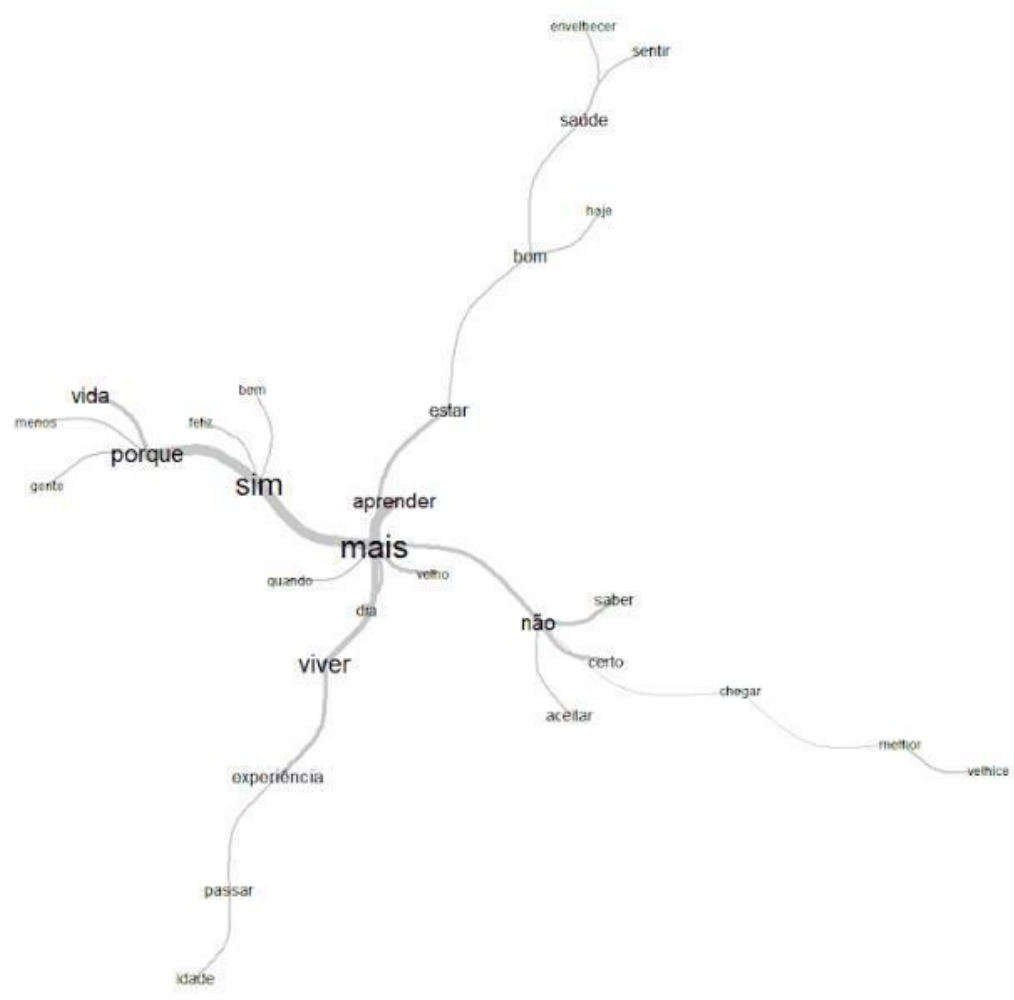

Figura 3. Combinação entre as palavras do conteúdo no momento pós-intervenção dos idososdo grupo NeuroCog-Idoso

Fonte: Dados gerados pelo software IRaMuTeQ a partir da análise dos resultados das entrevistas pós-intervenção. 
Na Figura 3, que apresenta o momento após as intervenções físicas e cognitivas (de ambos os grupos Stimullus e MEMO), o "mais" continua no centro de maior frequência. Entretanto, algumas associações se modificaram, e desta vez as mais utilizadas foram: "mais sim", "mais aprender", "mais não" e "mais viver". Assim, entendendo que o "mais" foi aumentado em frequência, assim como, em suas conexões com palavras positivas dentro do contexto de um grupo de idosos e da percepção do tempo no processo de envelhecer. Os termos popularmente usados para referir-se a tempo estão mais distantes do centro de frequência.

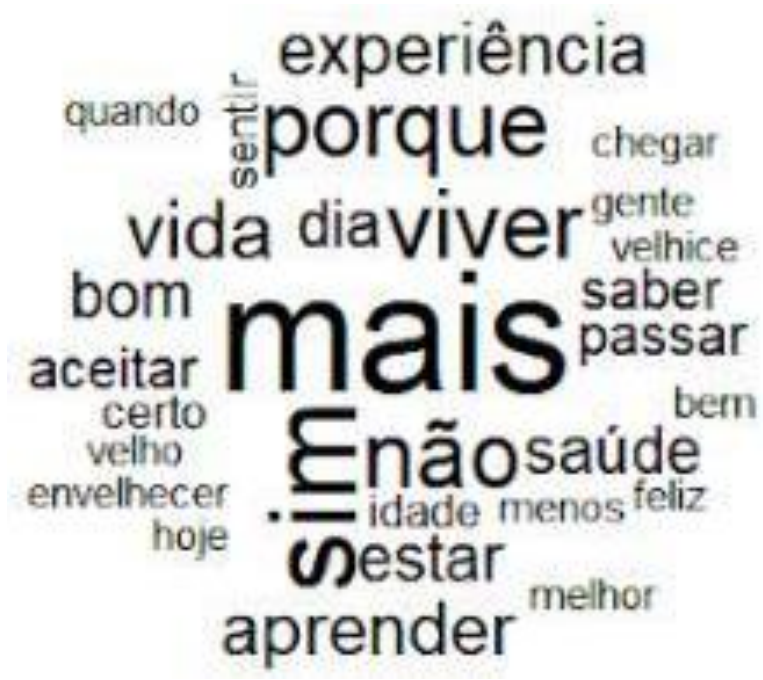

Figura 4. Nuvem de palavras do conteúdo no momento pós-intervenção dos idosos do grupo NeuroCog-Idoso

Fonte: Dados gerados pelo software IRaMuTeQ a partir da análise dos resultados das entrevistas pós-intervenção

$\mathrm{Na}$ Figura 4, a palavra "mais" continua sendo a de maior frequência de utilização. Contudo, quando comparado ao momento 1 (pré), o "sim" superou o "não", em conjunto com "porque", "experiência", "Viver", "bom", "aprender" e "aceitar". Nessa segunda coleta, mudou-se o uso e a frequência das palavras secundárias, indicativo de mudança na percepção dos integrantes dentro de uma construção semântica mais positiva, referente ao processo de envelhecer.
Contrapondo os dois momentos, o termo "mais" foi o mais frequente entre os idosos. O processo de envelhecimento é associado a acréscimos (sejam eles positivos ou negativos), o "não" em evidência no momento pré dará possibilidade de associações negativas ao envelhecer, inferindo uma percepção do tempo prejudicada. A mudança para o "sim" no momento seguinte refere-se a melhor aceitação do processo, possivelmente, devido às intervenções cognitivas, pedagógicas e físicas realizadas no período.

\section{Discussão}

É de suma importância recorrer à perspectiva dos idosos para ir contra o movimento social de perceber e subjugar a velhice sobre um estereótipo negativo. A autopercepção do idoso sobre o "estar" nesse momento é importante para confrontar essa perspectiva cultural e consolidar representações positivas, já que ele não se sente enquadrado nessa construção negativa, principalmente aquele inserido em processos que visem a uma busca de qualidade de vida (Silva Jardim, Medeiros, \& Brito, 2006).

Como visto, a memória é fundamental para a percepção do tempo que está intimamente ligada ao bem-estar no processo de envelhecimento, independente da estrutura teórica utilizada. O declínio dos processos mnemônicos, geralmente associado ao envelhecimento, altera a percepção da passagem do tempo e, consequentemente, sua vivência. Fatores como esquecimento, não se recordar, ou falas como "eu sei o que é, mas não consigo dizer" estão interligados a esta dificuldade.

É através dos órgãos sensoriais que os estímulos do meio chegam até o SNC, responsável pelo processamento da percepção, logo, um déficit significativo desses representa problemas para percepção do envelhecimento, já que muitos idosos direcionam sua atenção aos declínios e o tempo é associado aos problemas, e o tempo se torna sinônimo de "dor" ou "dificuldade" (Ribeiro, Alves, \& 
Meira, 2009). A percepção de um envelhecimento "positivo" deriva-se da ideia de prazer e felicidade, situações onde a atenção está direcionada a relações afetivas e/ou momentos de autonomia.

Prazer e dor são temas, ainda que de forma secundária, preponderantes para a percepção do tempo através do envelhecimento. Um bom exemplo é a condição socioeconômica do idoso: aqueles que estão em um quadro de riqueza tendem a ter uma expectativa de vida de 10 anos a mais, quando comparado a um pobre; este, por sua vez, tende a se manter no mercado de trabalho, muitas vezes informalmente, mais suscetível a problemas de saúde física e mental. Aqueles em condição financeira mais confortável tendem a usufruir de seu tempo com desejos mais prazerosos, associando a passagem do tempo a afetos mais positivos, evidenciando, assim, uma melhor qualidade de vida. Por outro lado, aqueles que estão na faixa de pobreza associam a passagem de tempo, com isso o processo de envelhecimento, a afetos, e utilizam palavras para defini-los com valores negativos (Mantovani, 2015; Menna-Barreto et al., 1990).

Contudo, cabe salientar que se faz necessário entender a relação de prazer e sofrimento no decorrer da vivência do idoso. Como visto anteriormente, a atenção e a memória são fatores cruciais para a percepção da passagem do tempo. Independentemente da condição financeira, já que se a atividade a ser executada (lazer ou trabalho) passa por um crivo psicológico do sujeito, manter-se no trabalho pode ser muito prazeroso ao idoso tanto quanto uma atividade de lazer (Mantovani, 2015; Menna-Barreto et al., 1990).

Durante o processo de envelhecimento, a resposta à percepção de estímulos temporais sofre pequenas mudanças, principalmente levando em consideração as alterações fisiológicas oriundas desse processo. Como exemplo: o espaço temporal entre o despertar e o adormecer (ciclo atividade/repouso) é alterado se comparado à juventude, assim como a duração do sono, os idosos tendem a dormir mais cedo e acordar mais cedo; estão mais vulneráveis a mudanças corpóreas de temperatura, pois estão mais suscetíveis aos estímulos ambientais; as dinâmicas que envolvem o sono dos idosos (dificuldade de iniciar e manter o sono, ter o sono mais leve etc.) afetam diretamente o controle da temperatura corporal, como os entraves do sangue para chegar às extremidades do corpo; o esfriamento da pele modula regiões do cérebro responsáveis pela vigília (Bueno \& Wey, 2012).

Sendo a temperatura corporal um dos fatores proeminentes para a percepção do tempo, existe um indicativo de que o momento em que o idoso é requisitado a responder esta pergunta pode ser um ponto dificultador à coleta de dados da pesquisa. O período do dia pode interferir na resposta, parece haver uma diferença entre dados coletados pela manhã daqueles realizados à tarde. $\mathrm{O}$ gênero também pode ser outro fator atravessador, já que a amplitude temporal das mulheres é maior do que os homens, pelo estilo de vida (Bueno \& Wey, 2012; Miguel, 2012).

A autopercepção de idade também é um fator atravessador para a coleta dos dados. Idosos que se percebem com uma idade mais nova que a cronológica definem o tempo em uma passagem mais rápida. Já para aqueles que se autodefinem como "velhos", o tempo passou mais devagar (Baum, Boxley, \& Sokolowski, 1984; Bertamoni, 2009).

Trabalhos como Antunes et al. (2006), Chariglione (2014), Galvão, Cunha Filho, Costa, \& Falcão (2010) e Nascimento-Castro, Gil-Mohapel, e Brocardo (2017) evidenciam a significativa melhora cognitiva em idosos que praticam exercícios cognitivos, físicos e sociais regularmente. De alguma forma, o sistema de percepção temporal também se mantém preservado, a melhora física e mental parece ser um atenuador da degradação deste processo (Bueno \& Wey, 2012). A mudança entre as associações de palavras ao "mais" do "não" para o "sim" pode ser explicado da mudança cognitiva dos idosos após passarem pelas atividades. 
O tempo é percebido de forma acelerada, superestimado, de acordo com o processo de envelhecimento. Deve-se a isto o declínio biológico, que acaba por influenciar o aparato cognitivo fazendo com que a atenção direcionada à detecção do tempo seja prejudicada. Consequentemente, dar-se-á que o tempo passe mais rápido, já que o indivíduo está disperso aos acontecimentos ao seu redor, podendo, assim, inferir que o tempo passa mais rápido para os idosos (Miguel, 2012).

Segundo Baum et al. (1984), dois outros fatores podem alterar a percepção de tempo através do envelhecimento: a depressão e a institucionalização. Eles encontraram dados de que idosos depressivos tendiam a superestimar a passagem do tempo e, de acordo com a melhora desse estado, o tempo iria se lentificando. Em contrapartida, os idosos que se encontram institucionalizados percebiam a passagem do tempo e o envelhecimento de forma mais morosa do que aqueles não institucionalizados, inferindo que idosos que fiquem mais tempo em casa sem atividades também possuem essa tendência subestimada a respeito do tempo. Outro ponto que corrobora com os dados encontrados é que idosos que possuem um propósito ao qual se dediquem, percebem o tempo de modo acelerado, diferentemente daqueles que não possuem. De uma forma geral, a independência/autonomia interfere diretamente no processo temporal.

Os participantes de projeto, em sua maioria, relataram não exercer atividades antes. Com a inserção das atividades no seu cotidiano, é natural o processo de percepção temporal também ser alterada, já que os exercícios propostos possuem uma continuidade fora do ambiente de execução do projeto e frequência nas práticas, fornecendo, assim, um objetivo a ser alcançado. Portanto, infere-se que a mudança na prevalência de palavras entre os momentos é dada a partir da inserção dos idosos nas atividades, com uma melhora cognitiva e física significativa, além de uma melhor compreensão sobre o processo de envelhecer, seus pontos positivos e suas limitações. Relatos como um aumento na qualidade de vida, no sono, na sociabilidade, na saúde mental e física são presentes no decorrer do projeto, afetando diretamente a percepção do tempo pelos participantes.

A alta frequência da palavra "experiência" e "aprender", principalmente no segundo momento, corrobora com a proposta de Menna-Barreto, Ades e Pesavento (1990). A experiência e a aprendizagem estão intimamente interligadas com acréscimos de eventos por um determinado período de tempo. São tarefas que deslocam e concentram a atenção para um determinado objetivo, não restando uma economia de foco para a percepção de passagem temporal. Abrangendo o modelo retrospectivo de percepção temporal, onde utiliza-se mais da memória, considerando que o público-alvo foram idosos, segue-se a premissa de que se passaram inúmeros eventos na vida desses sujeitos. Logo, quanto mais memórias foram evocadas, o tempo tende a ser percebido como maior. Aqui é possível correlacionar com autopercepção de idade, sendo diferente da cronológica, que também interfere na construção final do resultado.

Existe, ainda, uma possível vertente de que a percepção temporal esteja intimamente associada ao bem-estar biopsicossocial. A melhora da condição psicológica leva a ter experiência temporal mais acelerada. Portanto, a recordação e o afeto associado a ele, quando evocados e verbalizados como percepção do tempo, estarão associados à condição de vida experienciada pelo indivíduo. $\mathrm{O}$ modo de perceber a vida e o processo de envelhecimento devem-se a um bem-estar, sendo um fator mensurador, prevalecendo a correlação entre saúde psicológica x percepção do tempo (Baum et al., 1984).

\section{Conclusão}

A premissa "percepção do tempo" demonstrou ser uma importante mensuradora de qualidade de vida em idosos, já que sua exposição resultante está amarrada a diversos fatores cognitivos, físicos e emocionais. É uma variável com gigantesca amplitude, uma vez que o exercício de comparação e evocação com o passado e a memória se fazem necessários 
para a produção de um resultado, que é inestimável para a sobrevivência do indivíduo. Logo, a percepção do tempo possui um fator crucial para o sucesso de determinados comportamentos complexos, consequentemente, para a sobrevivência do sujeito. É clara a interligação com a qualidade de vida, que é a busca de todo ser humano, envelhecer de modo saudável.

Palavras como experiência e vivência são frequentes nos discursos dos idosos, e ambas estão intimamente relacionadas à percepção do tempo, associadas ao olhar do sujeito perante os afetos ligados aos momentos, levando a qualidade emocional nos registros da memória. As produções científicas são escassas sob esta perspectiva. O impedimento de comparação de dados é um fator limitador para novas correlações e fomentações. O tempo, em suas dimensões, implica para a sobrevivência e agora se abrem novos olhares para viver com qualidade.

Publicar a respeito do tema seria como abdicar da infeliz postura social, de entrelaçar o processo de envelhecimento, idoso, velho e envelhecer a ideias e conceitos pejorativos e/ou inúteis. É de suma importância romper com paradigmas sociais, sob as duas vertentes, o olhar do idoso sobre si e do outro em processo de envelhecimento a respeito da pessoa envelhecida. Pesquisas sob este conteúdo chamam a atenção para que o desenvolvimento até alcançar ao idoso é importante, mas que sempre existe um processo para se chegar lá, e esta caminhada pode ser o que definirá o resultado final. Ter uma qualidade de vida quando idoso dependerá de como se viveu o processo temporal, uma vez que será o momento de usufruir o presente, flutuando, a todo o momento, com as evocações da memória.

\section{Referências}

Antunes, H. K. M. et al. (2008). Exercício físico e função cognitiva: uma revisão. Revista Brasileira de Medicina do Esporte, 12(2), 108-114. Recuperado de http://www.scielo.br/pdf/rbme/v12n2/v12n $\underline{2 \mathrm{a} 11}$

Baum, S. K., Boxley, R. L., \& Sokolowski, M. (1984). Time perception and psychological well-being in the elderly. Psychiatric Quarterly, 56(1), 54-61.

Bear, M. F., Connors, B. W., \& Paradiso, M. A. (2008). Neurociências: Desvendando o Sistema Nervoso ( $3^{\mathrm{a}}$ ed.). Porto Alegre: Artmed.

Berne, R. M. et al. (2004). Fisiologia (5 $5^{\mathrm{a}}$ ed.). Rio de Janeiro: Elsevier.

Bertamoni, H. F. G. (2009). Entre Cronos e Kairós: a auto-percepção da idade na velhice (Dissertação de mestrado). Pontifícia Universidade Católica de São Paulo, São Paulo.

Bueno, C., \& Wey, D. (2012). Gênese e Ontogênese do ritmo de sono/vigília em humanos. Revista da Biologia, 9(3), 62-67. doi: $10.7594 /$ revbio.09.03.12
Buhusi, C. V., \& Meck, W. H. (2005). What makes us tick? Functional and neural mechanisms of interval timing. Nature Reviews Neuroscience, 6, 755-765.

Camargo, B. V., \& Justo, A. M. (2013). IRAMUTEQ: um software gratuito para análise de dados textuais. Temas em Psicologia, 21(2), 513-518. doi: 10.9788/TP2013.2-16

Chariglione, I. P. F. S. (2014). Intervenções cognitivas para o aprimoramento da memória em idosos com envelhecimento cognitivo normal (Tese de doutorado). Universidade de Brasília, Brasília.

Esperidião-Antonio, V. et al. (2008). Neurobiologia das emoções. Revista de Psiquiatria Clínica, 35(2), 55-65.

Ferreira, O. G. L., Maciel, S. C., Silva, A. O., Sá, R. C. N., \& Moreira, M. A. S. P. (2010). Significados atribuídos ao envelhecimento: idoso, velho e idoso ativo. Psico-USF, 15(3), 357-364. doi: 10.1590/S1413-82712010000300009

França, C. B. S., Barbosa, R. F. M., Fett, W. C. R., \& Fett, C. A. (2016). Exercício físico e envelhecimento: a percepção de idosas 
quanto à imagem corporal. Journal Health NPEPS, 1(1), 94-108. Recuperado de

https://periodicos.unemat.br/index.php/jhnpep s/article/view/1559

Fuentes, D. et al. (2008). Neuropsicologia: teoria e prática. Porto Alegre: Artmed.

Galvão, J. S. G. R., Cunha Filho, M., Costa, K. B., \& Falcão, A. P. S. T. (2010). Exercício Físico e suas implicações nas funções cognitivas: uma revisão sistemática. Fiep Bulletin, 80 (Edição especial). Recuperado de http://www.fiepbulletin.net/index.php/fiepb ulletin/article/viewFile/1060/2055

Gonçalves, R. C., \& Marques, M. D. (2012). Ritmos de populações: o caso das abelhas sem ferrão. Revista da Biologia, 9(3), 5357. doi: $10.7594 /$ revbio.09.03.10

Instituto Brasileiro de Geografia e Estatística [IBGE]. (2018). Projeção da população do Brasil e das Unidades da Federação. Recuperado de https://www.ibge.gov.br/apps/populacao/pr ojecao/

Izquierdo, I. (2011). Memória (2 $2^{\mathrm{a}}$ ed.). Porto Alegre: Artmed.

Kandel, E. R., Schwartz, J. H., Jessell, T. M. (2003). Princípios da Neurociência ( $4^{\mathrm{a}}$ ed.). São Paulo: Manole.

Mantovani, E. P. (2015). Satisfação com a vida, condições e autoavaliação da saúde entre idosos residentes na comunidade. (Tese de doutorado), UNICAMP, Campinas.

Martynhak, B. J., Back, F. A., Louzada, F. (2012). O valor biológico do período circadiano. Revista da Biologia, 9(3), 5861. doi: 10.7594/revbio.09.03.11

Menna-Barreto, L., Ades, C., \& Pesavento, S. J. (1990). Estudos sobre o tempo: Os tempos biológico, psicológico e social. São Paulo: Instituto de Estudos Avançados/USP. Recuperado de http://www.iea.usp.br/pesquisa/gruposanteriores/estudos-sobre-o-tempo
Miguel, M. A. L. (2012). Estimativa de tempo em humanos: bases, ontogênese e variação diária. Ritmos de populações: o caso das abelhas sem ferrão. Revista da Biologia, 9(3), 74-79. doi: 10.7594/revbio.09.03.14

Nascimento-Castro, C. P., Gil-Mohapel, J., \& Brocardo, P. S. (2017). Exercício físico e neuroplasticidade hipocampal: Revisão de literatura. Vittalle - Revista de Ciências da Saúde, 29(2), 57-78. doi: 10.14295/vittalle.v29i2.7461

Papaléo Netto, M. (2013). O estudo da velhice: histórico, definição do campo e termos básicos.

In E. V. Freitas, \& L. Py (Eds.), Tratado de Geriatria e Gerontologia (pp. 62-75).

Recuperado de https://ftramonmartins.files.wordpress.com/ 2016/09/tratado-de-geriatria-egerontologia-3c2aa-ed.pdf

Purves, D. et al. (2010). Neurociências (4a ed.). Porto Alegre: Artmed.

Ribeiro, L. C. C., Alves, P. B., Meira, E. P. (2009). Percepção dos idosos sobre as alterações fisiológicas do envelhecimento. Ciência, cuidado e saúde, 2(8), 220-227. doi: 10.4025/cienccuidsaude.v8i2.8202 .

Sampaio, T. O. M. (2016). Percepção do tempo: da psicologia para psicolinguística. Letras hoje, 51(3), 374-383. doi: 10.15448/1984-7726.2016.3.22264

Santos, S. S. C. (2010). Concepções teóricofilosóficas sobre envelhecimento, velhice, idoso e enfermagem gerontogeriátrica. Revista Brasileira de Enfermagem, 63(6), 1035-1039. doi: $10.1590 /$ S003471672010000600025

Schiffman, H. R. (2005). Sensação e percepção ( $5^{\mathrm{a}}$ ed.). Rio de Janeiro: LTC.

Silva Jardim, V. C. F, Medeiros, B. F., Brito, A. M. (2006). Um olhar sobre o processo do envelhecimento: a percepção de idosos sobre a velhice. Revista Brasileira de Geriatria e Gerontologia, 9(2), 22-34.

Sternberg, R. J. (2012). Psicologia Cognitiva. São Paulo: Cenage Learning. 


\section{Dados sobre os autores:}

- Danilo Ribeiro do Nascimento Aragão: Biólogo e Psicólogo pela Universidade Católica de Brasília, Brasília, DF, Brasil. Membro do Grupo de Pesquisa CNPq NeuroCog-Idoso.

- Isabelle Patriciá Freitas Soares Chariglione: Psicóloga, Doutora em Cognição e Neurociências pela Universidade de Brasília. Professora da Graduação em Psicologia e da Pós-graduação em Gerontologia pela Universidade Católica de Brasília, Brasília, DF, Brasil. Coordenadora do Grupo de Pesquisa CNPq NeuroCog-Idoso.

\section{Agradecimentos:}

Essa presente pesquisa foi realizada graças ao apoio e aprovação nº: 0193.001227/2016 da Fundação de Apoio à Pesquisa do Distrito Federal - FAPDF. 